\title{
TRADUÇÃO COMO INICIAÇÃO
}

\author{
Evelyn Schuler Zea* \\ Universidade Federal de Santa Catarina
}

\begin{abstract}
Resumo: De forma cada vez mais notória, a tradução aparece como processo, dispositivo ou configuração não limitada à dimensão textual, mas inserida no âmbito mais amplo de trocas rituais, sociais e técnicas. Eis um momento de transbordamento ou expansão da tradução que demanda uma atenção específica. Tal acontecer extratextual da tradução é tomado aqui como motivo para repensar a prática e a conceitualização da tradução sob a figura da iniciação xamânica. Concretamente, se trata de elaborar articulações do evento da iniciação xamânica narrada em $A$ queda do céu (Kopenawa; Albert, 2010, 2013, 2015), destacando questões do acesso à alteridade, a interlocução com ela e as vias da transformação que atravessam o duplo campo da antropologia e da tradução.

Palavras-chave: Antropologia. Iniciação. Tradução. Transformação. Xamanismo.
\end{abstract}

\section{TRANSLATION AS INICIATION}

\begin{abstract}
In an increasingly noteworthy manner translation appears as a process, device or configuration that is not limited do textual dimension, but inserted in the wider context of ritual, social and technical exchanges. This is a moment of overflowing or expansion of translation, which requires a specific attention. This extratextual proceeding of translation
\end{abstract}

\footnotetext{
* Professora doutora (2006) em Antropologia Social pela Universidade de Bern, Suíça. Pós-doutora (2010) pela Universidade de São Paulo (USP). Atualmente é professora no Departamento de Antropologia, no Programa de Pós-graduação em Antropologia Social e na Pós-Graduação em Estudos da Tradução na Universidade Federal de Santa Catarina (UFSC). Florianópolis, Santa Catarina, Brasil. E-mail: evelynsz@gmail.com
} 
is taken here as a motif to rethink the practice and conceptualization of translation under the figure of shamanic initiation. Specifically, the purpose here is to elaborate articulations in the event of shamanic initiation as narrated in The falling sky (Kopenawa \& Albert, 2010, 2013, 2015), emphasizing questions of access to otherness, interlocution with it and the ways of transformation that traverse the double field of anthropology and translation.

Key words: Anthropology. Initiation. Translation. Transformation. Shamanism.

The most difficult place to perform is one's home place (Glenn Gould)

Tradução como iniciação ${ }^{l}$ é o título escolhido por sua simplicidade. Mas como quase todo título ele é, ao mesmo tempo, uma simplificação. Pois onde tem dois sempre ronda um terceiro e aqui se trata efetivamente de um triângulo de referências, onde além da tradução e da iniciação também a antropologia ocupa um outro vértice. De modo que as figuras que serão convocadas aqui são as do xamã, do antropólogo e do tradutor. O título é ainda tanto uma proposição - tradução como iniciação - como também uma questão, no sentido de que o que propõe é pensar a interlocução desses termos. Em outras palavras, trata-se aqui de ensaiar ver até onde podemos chegar através do esquema da iniciação para repensar a antropologia, a tradução e, especialmente, o trato entre elas. Tudo isto depende, obviamente, de qual seja esse esquema da iniciação e a isso vou dedicar a primeira parte deste pequeno ensaio, isto é, à descrição e análise da iniciação tal como ela foi narrada em A queda do céu (Kopenawa; Albert, 2010, 2013, 2015) um "tex-

\footnotetext{
${ }^{1}$ Este pequeno ensaio é uma versão revisada da conferência “A tradução como iniciação" que apresentei no dia 10 de setembro de 2015 na abertura do V Transfusão - Encontro de Tradutores Literários da Casa Guilherme de Almeida: Tradução e Antropologia (cf. http://www.casaguilhermedealmeida.org.br/ arquivos/transfusao-2015programa-definitivoterceirorev-ao19815definitivo.pdf).
} 
to escrito/falado a dois" (2015, p. 537), entre o xamã yanomami Davi Kopenawa e o antropólogo francês Bruce Albert. ${ }^{2}$ Daí vou proceder à elaboração e formalização da iniciação que me permita na segunda parte contrastar seus alcances com algumas concepções sobre a tradução cultural, num caso com ênfase na parte da tradução, no outro na parte da antropologia. Ao longo desse contraponto espero poder desdobrar o motivo da iniciação como modo de chegar na parte final com algumas propostas sobre a questão do acesso e da transformação, que me parece atravessar o duplo campo da antropologia e tradução.

Essa é a proposta e, em certa forma, o ponto de partida, mas nunca se parte de zero e não vou negar que também respondo com essa proposta a uma dupla perplexidade.

A primeira tem a ver com parte de La chute du ciel, que tem entre suas várias virtudes incluir diversos suplementos de grande relevância, que complementam a riqueza do relato de Davi Kopenawa. Num desses suplementos, Bruce Albert oferece uma análise elaborada e ao mesmo tempo um testemunho do trabalho realizado com Davi Kopenawa. Na edição francesa (2010), que é a primeira, esta seção aparece sob o título Post-scriptum: Lorsque je est un autre (et vice versa), enquanto na edição em inglês (2013), deixando de lado a alusão rimbaudiana, aparece sob o rótulo quase puramente técnico de How this book was written. ${ }^{3}$ Esta seção traz grandes contribuições, mas discordo de vários apontamentos apresentados

2 Trata-se de uma obra excepcional por sua relevância na antropologia, já que oferece uma densa e extensa mensagem cosmológica ou interpelação xamânica dirigida ao mundo dos brancos. No mais, considero que a obra pode interessar particularmente no duplo campo da tradução e antropologia, entre outras coisas, porque se trata de um livro cujo original constitui já uma tradução, o que faz da tradução um original na medida em que o texto inicial é produto da transposição ao francês do discurso yanomami de Davi Kopenawa a instancias de tópicos sugeridos por Bruce Albert (2010, p. 19).

3 A alusão rimbaudiana é mantida na tradução de Beatriz Perrone-Moisés: Postscriptum Quando eu é um outro (e vice-versa) publicada na edição em português em agosto de 2015 (cf. Kopenawa; Albert, 2015, p. 512). 
aí. O que, certamente, não tem por que ser especialmente importante. Mas tem algo mais e é o fato, a meu parecer injustificado, que nesse Post-scriptum, onde um dos temas com maior destaque é a tradução, Bruce Albert não cita nem recorre a orientações que sobre vários motivos muito próximos - como o acesso à alteridade, a interlocução com ela ou a via da transformação - são apresentadas no relato de Davi Kopenawa que constitui a parte principal do livro. Este é um primeiro efeito desconcertante: como assim o antropólogo e tradutor não recorre às conceitualizações nativas que se encontram no relato de Kopenawa, ao tratar do enfoque da antropologia e da tradução?

O segundo desconcerto também tem a ver com La chute du ciel, mas em outro contexto. E, de passagem, também merece atenção o uso desta expressão do "ter a ver", uma fórmula que é um recurso muito frequente, mas pouco atendido. Que é o que se quer dizer com este "ter a ver"? que algo "tem a ver com outra coisa"? Duvido bastante que seja simplesmente outra forma de dizer "relação", que algo se "relaciona" com outra coisa. Talvez, digo isso apenas como sugestão, se trata de que uma coisa e outra tenham algo para ver conjuntamente ou, inclusive, que precisam ver algo conjuntamente. É uma possibilidade que, no meu caso, dá lugar a uma expectativa. E isto mesmo foi o que ocorreu quando vi o índice de uma publicação de crescente circulação, a revista Hau: Journal of Ethnographic Theory que, num dos seus números recentes $^{4}$, incluía três dossiês, dos quais um era explicitamente sobre tradução e antropologia (um dossiê intitulado Translating Worlds: The epistemological space of translation), e outro justamente um Book Symposium sobre La chute du ciel. Um dossiê ao lado do outro, ambos de grande elaboração e, no entanto, apresentados sem ter a ver entre si, sem ver conjuntamente ou sem deixar-se ver conjuntamente; de novo, fica a impressão que a tradução do antropólogo ignora aí as orientações de uma eventual tradução nativa.

${ }^{4} \mathrm{Cf}$. http://www.haujournal.org/index.php/hau/issue/view/hau4.2. Esse número da revista também foi publicado como livro editado por Hanks \& Severi (2015).

Cad. Trad., Florianópolis, v. 36, nº 3, p. 192-212, set.-dez./2016 
Mas por que essa desatenção? Pode ser que tais traduções não têm efetivamente nada a ver mutuamente, mas também pode ser que a proximidade excessiva lhes impeça ver-se uma em outra. Em todo caso, esta conjunção e disjunção simultâneas, esta coincidência neutralizada da antropologia e tradução me parecem desconcertantes e conformam os contra motivos deste pequeno ensaio.

\section{I}

Começo então com a primeira parte expondo de modo condensado o processo da iniciação xamânica narrada em La chute du ciel. Trata-se, concretamente, da iniciação experimentada por Davi Kopenawa sob a guia do seu sogro Lourival na aldeia yanomami de Watoriki. Devo fazer já mais um esclarecimento (inclusive sob o risco de não fazer mais do que esclarecimentos neste ensaio). Quero dizer que até aqui, inclusive no título, falo da iniciação e efetivamente se trata dela, mas não do conjunto da iniciação, do princípio até o fim dela. Do que se trata, e devo enfatizá-lo, é especificamente do segmento inicial, preliminar da iniciação, que proponho distinguir sob o rótulo específico do início da iniciação. A razão desta distinção é que é nesse segmento onde, tal como espero mostrar, se resolvem as condições de possibilidade da iniciação, suas exigências decisivas, tudo o que ela demanda de quem se inicia. Esta fase crucial se estende desde a ingestão da yãkoana, o pó alucinógeno, até o momento em que os xapiri ou espíritos aliados finalmente se manifestam diante o iniciado e procedem a transmitir-lhe os cantos e danças do saber xamânico. O que segue também faz parte da iniciação, mas se trata já de um processo de aprendizagem contínuo e, no entanto, sobre o que gostaria de chamar a atenção é sobre as descontinuidades, sobre o desconhecimento prévio ao conhecimento, sobre a desfiguração anterior à configuração do novo xamã. Neste segmento inicial, o iniciado se vê exposto inesperadamente aos violentos ataques dos xapiri que o reduzem de forma cada vez mais aguda à uma expressão mínima, a uma sombra de si mesmo, 
a um estado parecido à morte se não fosse por um resto ínfimo a partir do qual, no entanto, a reconstituição e a sobrevida do xamã se mostram novamente possíveis. E o que busco circunscrever neste momento inicial extremo, nessa condição radical, é justamente esse último remanente do iniciado que ao mesmo tempo constitui a potência que, de modo imprevisível, lhe permite um novo começo.

Mas vejamos este processo concretamente - em suas dimensões física, emocional, material e conceitual - no relato que Davi Kopenawa nos oferece de sua experiência. Já o primeiro momento dela é veemente. Pois logo depois de ter ingerido a yãkoana, Kopenawa sente um forte golpe na nuca que o derruba e lhe faz perder tanto o equilíbrio como a consciência, a articulação tanto do corpo como da fala. Kopenawa se vê repentinamente exposto ao embate de dor e de terror, ao sofrimento do corpo e à uma crescente incerteza sobre sua condição. A deterioração se agudiza na medida em que que o transe avança e Kopenawa fica cada vez mais derrotado, sem maior pulsão que o movimento com que oferece suas narinas a uma nova inalação da yãkoana, ao mesmo tempo em que consegue apenas sussurrar "Aaaa! Estou virando outro! Aaaa" (KOPENAWA; ALBERT, 2015, p. 136). De fato, prostrado, jogado no chão, coberto de pó e secreção, Kopenawa não reconhece seu entorno nem seus familiares e é visto por eles com consternação. A cena sugere que também os laços de pertença de Kopenawa se tornam precários e que esse isolamento é - até esse momento - o único sentido de virar outro. Tudo isso põe ao mesmo tempo em evidencia que a iniciação, mais que uma promessa dos xapiri ou uma transação ritual com eles, é uma eventualidade, ou seja, um evento cuja resolução é intrinsicamente aberta, imprevisível. Não é um caminho disponível, mas um abismo. Tanto assim que essa sequência de perdas na qual até aqui parece consistir o início da iniciação, motiva Kopenawa a se perguntar cheio de angústia por que os espíritos não se manifestam diante dele e faz que inclusive chegue a considerar a impostura - que ele logo descarta - de simplesmente fingir que se encontrou com os xapiri para assim por um fim de uma vez ao seu transe agoniado. “Akaaa! Akaaa!” - geme Kopenawa, rolado no 
chão e se contorcendo de pavor: "Apesar de eu ter virado fantasma, os xapiri ainda permaneciam invisíveis. [...]: Por que ainda não vejo nada?" (2015, p. 145).

Devir-espectro sinaliza uma forma extrema de precariedade no final de uma sequência de sucessivas subtrações. Não é algo que acontece de um momento a outro, através de uma única ruptura, mas é um processo diverso e insistente. Supõe a perda do controle do corpo. Supõe a quebra de relações ou, melhor dito, de formas de pertença no que diz respeito a um lugar e a uma comunidade. E supõe assumir a ruina do saber comum, a desorientação e, em consequência, o prosseguir sem coordenadas, ainda quando o conhecimento disponível tenha ficado atrás. Contudo, é nesse mesmo estado de extrema precariedade e extravio no qual finalmente acontece a magnífica aparição dos xapiri, que são intercessores de um mundo pletórico de ornamentos e sonoridades. É a partir de sua chegada que as árvores começam a falar ao iniciado e as folhas o tocam "como mãos" (2015, p. 102), e se confirma a transformação do iniciado num novo xamã. E a pergunta que se impõe então é: como é possível essa inflexão? Como é possível que a partir de quase nada tudo seja possível novamente?

Até aqui segui o curso do relato de Kopenawa. Mas se tivéssemos que pensar o início da iniciação perguntando-nos que é o que trata, ou seja, perguntando-nos de que se trata na iniciação, não seria infundado que respondêssemos que o que se busca através dela é ou o acesso ao mundo dos espíritos protetores ou a transformação do iniciado em xamã. Basta lembrar a demanda angustiada de Kopenawa pela aparição dos xapiri ou seu clamor, mesmo bastante débil e frágil, de virar outro. Com efeito, acesso e transformação são eventos concomitantes, ainda quando a ênfase possa variar entre eles. Parece pertinente destacar aqui questões, ou seja, reformular o processo da iniciação em termos de problemas porque desta forma deixamos de ver as articulações da iniciação como instâncias puramente empíricas e admitimos aí a elaboração e eficácia de dispositivos que podemos chamar de conceitos nativos. O que se obtém com esse enfoque são duas coisas. Por um lado, podemos 
ver que o que está em jogo - a transformação e o acesso - não são problemas nem tão peculiares nem tão insólitos, mas que atingem questões que persistem abertas tanto na antropologia como, a meu ver, na (teoria da) tradução. Por outro lado, com este enfoque é possível deter-se em configurações imprevisíveis e detectar nelas o rendimento de imagens conceituais, isto é, de configurações com efeitos conceituais. Uma delas, por exemplo, é a condição de espectro no início da iniciação, que por um lado aparece como uma figura deficitária, reduzida, mas por outro lado pode ser vista como uma fórmula constituinte que busca justamente responder aos desafios do acesso e transformação.

Afim de reforçar a proximidade dos motivos expostos da transformação e acesso, gostaria de introduzir três breves rodeios. $\mathrm{O}$ primeiro, referente ao motivo do acesso, toma como referência o amplo debate sobre a questão do correlacionismo, instigado pelo livro Après la finitude do filósofo Quentin Meillassoux (2008). Não vou entrar aqui nas respostas do livro, mas limitar-me às perguntas que coloca sobre como é possível aceder a algo que se encontra fora ou além de si mesmo sem ao mesmo tempo deformá-lo, distorcê-lo. De fato, o modelo da relação atualmente dominante não parece ter conseguido dissolver tais complicações, pois nele a relação por um lado nos oferece contato com a alteridade sendo, por outro lado, o filtro que condiciona nossa aproximação a ela e, mais ainda, a barreira que nos impede sair para a exterioridade, onde habitam outros seres na sua radical alteridade.

Essa questão do acesso tem sido reativada por Meillassoux, mas há muito tempo tem estado aí implicitamente. Mais remoto ainda é o impasse da transformação, ainda que também tenha recebido uma reformulação recente por parte de Terry Eagleton (2003). O problema neste caso é que aparentemente resulta impossível saber quando algo se transforma, porque se algo se transformou efetivamente o que vemos são simplesmente duas coisas diferentes, sem que possamos captar o momento da transformação; e se no caso contrário chegamos a reconhecer a mesma coisa do começo ao final, então o que ocorre é que a transformação de fato não se consumou plenamente. 
Seguindo mais um rodeio, encontramos uma transfiguração destas questões no esplêndido diálogo Eupalinos ou a arquitetu$r a$, escrito ao modo socrático por Paul Valéry (1996). Se trata de uma única e extensa conversa entre os espectros de Sócrates e Fedro, que já mortos Valéry imagina habitando na eternidade. São vários os temas que eles evocam no diálogo, mas um que se destaca é a perplexidade que Sócrates lembra de ter experimentado por causa de um objeto de origem incerta - l'objet inconnu - que ele encontrou um dia na praia quando era jovem. A forma desse objeto poderia ter sido produto do azar da erosão ou poderia provir do naufrágio de uma embarcação que transportava, entre outras, esta obra de um artista desconhecido. Em ambos casos, na sua indeterminação, esse objeto resulta de repente comparável, para Sócrates, com sua atual condição de espectro, na qual ele não pode ignorar que apesar da convicção com que expresse suas opiniões, é apenas questão de tempo - e tempo é o que sobra na eternidade - para que ele se desloque de uma certa posição a outra justamente contrária, pela erosão que o tempo exerce sobre qualquer modo de certeza. Esta exposição à contingência faz com que Sócrates reveja a certeza do saber absoluto ao qual dedicou sua vida e, revogando esta ilusão, assuma consequentemente a posição que ele mesmo denomina como a de um Anti-Sócrates, desta vez ao lado da precariedade da existência. O que incita a perguntar: o que pode ser aí tão perturbador como para transformar Sócrates, uma das figuras conceituais mais distinguidas e consistentes no Ocidente, na anti-figura de si mesmo? Na narrativa de Valéry este efeito é atribuído tanto ao poder dissolvente de l'objet inconnu, do objeto desconhecido, quanto à radical alteridade da condição espectral que é seu reflexo.

Tais os rodeios que, ainda que algo distantes, ouso delinear aqui porque imagino que os rodeios são maiormente bem-vindos na tradução, na medida que ela mesma pode ser considerada uma busca de rodeios ou como um rodeio perseverante. Mas não se pode escapar com isso à pergunta latente acerca do que é o que têm a ver concretamente esses rodeios - que ampliam motivos do início da 
iniciação - com a prática e a teoria da tradução. Esta é uma questão que obviamente depende de uma ideia da tradução e suspeito que definir a tradução é uma questão aberta que cada vez mostra maiores alcances, ao ponto que ao invés de chegar a definir a tradução é provável que seja ela a que termine por definir-nos. Não ignoro, por outra parte, que também entre os tradutores circulam diversas concepções sobre a sua tarefa. Por isso, gostaria de limitar-me aqui à seguinte proposição: a iniciação, ou o início dela, tem a ver com a tradução na medida em que esta seja concebida como uma forma de transformação e de acesso. Ou seja, a iniciação é relevante para a tradução, ou pode sê-lo, enquanto elaboração das exigências, meios e efeitos de acesso e de transformação. Pois, de fato, como pode um tradutor literário tratar um texto qualquer se antes não consegue de alguma maneira aceder a ele, se antes não consegue abrir uma passagem que lhe permita detectar ou captar as marcas da sua singularidade? Ao mesmo tempo, como conseguir esse acesso se não é por via de uma transformação de si mesmo que permita abrir-se, expor-se a seu objeto? Este é evidentemente um desafio análogo ao da intervenção do antropólogo, que busca justamente iniciar uma forma de interlocução com aqueles outros que encontra durante seu trabalho de campo. No mais, curiosamente, a antropologia tem recorrido também à metáfora da tradução no momento de imaginar-se o trabalho do xamã, do ex-iniciado. A figura do xamã como tradutor é de fato uma das mais recorrentes, mesmo que talvez nunca tenha sido de todo especificada. De tal modo que pensar a tradução como iniciação vem a ser uma forma de devolver essa visita da tradução ao xamanismo afim de que nesse ir e vir, nessas mútuas visitas metafóricas, talvez seja possível um ver e um deixar-se ver conjuntamente.

Retomando o anterior, podemos dizer que o que o início da iniciação mostra não é nada radicalmente novo, mas sim uma implicação radical e rigorosa: o fato que uma transformação qualquer, seja de si mesmo ou dos outros e do acesso entre uns e outros, demanda em troca que se assuma uma condição de precariedade extrema por efeito da dissolução de algumas de suas maiores garantias, 
tais como a certeza, a identidade, a pertença, que podem ser vistas em conjunto como outras tantas variantes da propriedade. Mas se isto é assim, então o que marca o início da iniciação é a passagem para o que sugiro chamar a impropriedade na medida que é isso que viria a emergir com a condição de espectro enquanto primeira figura de impropriedade. No que segue, tratarei de por a prova esta constelação.

\section{II}

Acho que não preciso manifestar uma vez mais meu apreço pelo trabalho de Bruce Albert em A queda do céu, mas é por isso mesmo que quis seguir mais de perto algumas das formulações sobre sua experiência de tradução cultural tal como elas aparecem no mencionado Post-scriptum. Na confecção do livro, Bruce Albert participa como entrevistador, transcritor, editor e tradutor, além de contribuir enormemente com seu conhecimento etnográfico dos Yanomami. Esta é uma intervenção sumamente complexa, mas é talvez possível decantar dela a parte do tradutor seguindo os matizes das fórmulas que ele adota para descrever seu trabalho com Davi Kopenawa.

Uma primeira fórmula geral é a que Bruce Albert denomina o "pacto etnográfico", pelo qual o antropólogo se compromete à transmissão e difusão do discurso nativo. Albert entende esse compromisso sob a figura do "truchement às avessas" (2015, p. 522), ou seja, do tradutor no interesse dos índios (os truchements eram brancos pobres que conviviam ou estavam familiarizados com os índios e por isso serviam de intérpretes na interlocução com funcionários ou colonizadores). Bruce Albert se reserva nesse pacto o direito de continuar cultivando paralelamente "sua própria curiosidade intelectual", que viria a ser a contraparte do antropólogo. Os termos deste acordo teriam figurado inclusive num "contrato de redação explícito", subscrito por Davi Kopenawa e Bruce Albert (2015, p. 535). 
No que diz respeito à composição do texto, Bruce Albert recorre à fórmula da "distance moyenne" (2010, p. 598), "a meio caminho" (2015, p. 545), ou seja, da equidistância seja entre o rigor etnográfico e o efeito estético, entre a fluidez e a peculiaridade ou entre o interesse de conseguir a maior audiência possível e a fidelidade à "alteridade singular" (2015, p. 537) do discurso. Se trata de uma postura cujo antecedente mais antigo deve ser aquela recomendação da Retórica de Aristóteles de manter o equilíbrio entre a claridade do familiar e a fascinação do estrangeiro, instituindo com isso outra variante da justeza do ponto médio. Aparece, no entanto, uma complicação no momento de considerar o uso da primeira pessoa no relato de Kopenawa. Esse é um recurso usual da literatura etnobiográfica que busca dar uma ilusão de transparência ou um efeito imediato ao relato, mas que fica difícil de sustentar admitindo ao mesmo tempo uma considerável intervenção no recorte, ampliação, seleção e ordenamento do texto. Daí que Bruce Albert reformule o nexo com Davi Kopenawa, assignando-se o papel de "alter ego redacteur" e assignando, implicitamente, o de ego narrador a seu interlocutor. Esse sensível deslizamento para um modo ancorado na identidade é confirmado em seguida por Bruce Albert ao anotar ainda que ambos atores, o narrador e o redator, "se empenham em ser um só" (2015, p. 537), ou seja, que são reconduzidos, na busca de se tornar um, a uma forma de unidade.

É instigante notar que nesse contexto se recorre também à figura de um "devir outro" tanto do redator quanto do relator por efeito da mútua transferência entre eles. Lembremos que "devir outro" é também um clamor de Davi Kopenawa na iniciação, consonância que poderia ter motivado mais de um enlace conceitual entre a iniciação e a reflexão sobre a tradução. Lembremos também que esta figura do "devir outro" aparecia no primeiro título do Post-scriptum: je est un autre, que depois foi suprimido. Mas sem esta afiliação rimbaudiana, como entender aqui esse "devir outro"? Outra formulação de Bruce Albert parece dar uma indicação incisiva a respeito, quando ele diz que ele, enquanto redator e tradutor, busca "poder habitar sua voz" (2015, p. 538), isto é, a do narrador. Che- 
gando a esse ponto me parece que a ênfase na identidade desta última figura sugere fortemente que a concepção do trabalho conjunto de Kopenawa e Albert é mobilizada por este último em direção a uma função de unidade com a alteridade. De tal modo que "devir outro" se converte aqui num "devir um e o mesmo" que o outro, ou seja, que, em virtude desse movimento de homogeneização, a identidade é reestabelecida exatamente ao mesmo tempo que se produz um deslocamento em direção ao outro.

Espero dar a entender claramente que não estou me referindo com isso ao que efetivamente acontece no trabalho conjunto de Davi Kopenawa e Bruce Albert. Na realidade penso que acontece bastante mais que o que transmite a análise de Bruce Albert no Post-scriptum. Mas acho que este é um testemunho significativo tanto da coautoria como, ao mesmo tempo, das dificuldades ao tratar motivos de acesso e transformação. Me parece evidente que também destas possibilidades se trata aqui: tanto da inquietude e mutua incumbência do antropólogo e do nativo como da alteração de cada uma das partes. E, mais uma vez, sobre o que gostaria de chamar a atenção é sobre a opção de repensar esta experiência a partir do "devir outro" da iniciação. Mas o que pode significar isso concretamente?

Talvez seja possível visualizar isso a partir de duas imagens que deixam uma marca no relato, já não de Davi Kopenawa, mas de Bruce Albert. A primeira é a imagem de um velho guayabero em trapos, que inesperadamente aparece um dia ao amanhecer para oferecer a Bruce Albert um prato de comida. Essa imagem, como Bruce Albert mesmo comenta, se converteu para ele numa imagem de referência, ou seja, na imagem através da qual ele se relacionava com um lugar específico, e uma imagem que ao mesmo tempo lhe reforçava a certeza de sua tarefa de antropólogo. Podemos contrastar esta com uma segunda cena na qual o antropólogo recém-chegado na aldeia entra na escuridão esfumaçada da maloca dos yanomami, onde é recebido a mordidas pelos cachorros até que seus anfitriões, que não dissimulam a hilaridade que lhes causa a situação, conduzem entre sombras ao desconcertado antropólo- 
go até sua rede. Duas situações e dois efeitos, um visivelmente confirmatório e outro perturbador, desequilibrante, que mostra o antropólogo sob uma luz vacilante.

Se vemos estas situações através já não dos termos da identidade, mas da precariedade no esquema da iniciação, não é difícil imaginar qual entre elas seria a cena primária que adotaríamos como chave da abordagem aqui proposta. Essa abordagem da tradução por via da incerteza, da sensação de perda, do eclipse de certezas dentro da maloca se torna talvez menos inusual se levarmos em consideração um dos textos mais notáveis da teoria da tradução. Me refiro à Tarefa do Tradutor, die Aufgabe des Übersetzers, de Walter Benjamin (2010), que já através do seu título condensa a complexidade da tradução: Aufgabe como entrega, como doação da tradução; Aufgabe como tarefa, como processo de elaboração; e, mais uma vez, Aufgabe como abandono, como desprendimento e renúncia - e de quem se não de si mesmo, do tradutor? -, enquanto exigências de sua condição e seu render-se.

De tal modo que a questão que se impõe é tentar ver, sem descartar o que pode trazer a via da certeza, se faz sentido arriscar-se também por essa via relegada da precariedade, que por sua vez se deixa sintetizar na condição de espectro. Esta formulação, com suas conotações de labilidade e desamparo, pode talvez dar a impressão de ter uma significação puramente negativa. No entanto, isso não seria justo nem congruente, já que a ela foi atribuída um rendimento específico: possibilitar a transformação e o acesso, efeitos que não podem prosseguir de uma mera limitação ou insolvência. Daí que sugeri dar um passo mais nessa direção no final da seção anterior introduzindo a fórmula da impropriedade. Com o que, obviamente, as dificuldades não apenas persistem, mas inclusive se agudizam, se radicalizam, porque é difícil falar (nomear) um termo mais denigrado que a impropriedade. Mas o problema não é meramente terminológico. No limite, o que há nas incriminações contra a impropriedade é um sintoma, um sinal inverso do que pode abrir a possibilidade de que precariedade e impropriedade não sejam derivadas e defectivas, mas 
formas recalcitrantes e inclusive alternativas ao predomínio do princípio da propriedade.

Até onde pode chegar a projeção da tradução provavelmente não é algo que se possa perceber linearmente, mas apenas detectar em ondas, tomando sempre novos impulsos e registros, seguindo trajetórias distintas e se-orientado pelos rastros que deixam. Inclusive na antropologia, que tem vivido longamente na vizinhança com a tradução, esta é uma questão que continua aberta e que tem sido motivo, recentemente, de uma nova proposta. Carlo Severi e William Hanks (2014) editaram o denso dossiê que mencionei no início, sob o título Translating Worlds. The epistemological space of translation, em cuja apresentação levantam a tradução como chave epistemológica para a antropologia e, mais ainda, como princípio epistemológico de validade geral (HANKS; SEVERI, 2014, p. 8-12).

Esta é uma proposta que amplia consideravelmente o conceito de tradução através de uma série de movimentos que se afastam rapidamente da ideia corrente da tradução como simples meio ou canal pelo qual conhecemos ou transmitimos um conhecimento. Um primeiro movimento nessa expansão é o reconhecimento do dinamismo da tradução dentro das fronteiras de uma mesma língua, ou seja, que ela não é mais uma atividade restringida à troca com um exterior linguístico. Para além - ou aquém - disso, a tradução também opera significativamente dentro do mundo familiar e circundante. $\mathrm{O}$ que conecta com o segundo movimento expansivo, segundo o qual: "translation is a constant and unavoidable part of any single culture, and not only a problem of comparison" (HANKS, 2014, p. 18). Ou seja, a tradução aqui não é mais apenas um meio comunicante, mas ao mesmo tempo um fator constitutivo e de eminente produtividade cultural. A partir disso podemos pensar que a tradução não é um fator ou uma dimensão secundária, mas que são suas transfusões as que animam a vida das culturas e, inclusive, que ela é a matéria da qual estamos feitos tanto uns como outros. Tudo isso demanda, no entanto, uma renovada aproximação à tarefa da tradução. 
Demasiado tempo, com efeito, a tradução tem sido vista predominantemente em função da continuidade, do suposto vínculo de identidade entre a tradução e o traduzido, sob a ideia de que o primeiro se limita a ser uma réplica do segundo. É este pressuposto de reprodução o que dá suporte, por exemplo, para a visão da tradução como uma tarefa subalterna, já que se a contribuição dela não é mais que uma réplica, se entende que perca toda relevância diante da presença efetiva do traduzido. Uma reconsideração do papel da tradução demanda, por isso, uma compreensão distinta do fator de descontinuidade nela. Entender que a tradução não apenas tem como ponto de partida uma descontinuidade, mas que também aponta para ela e que precisamente este momento da diferença com o "original" pode ser o de maior rendimento e elaboração da tradução.

Cada um destes movimentos de expansão - e há outros - nos vão aproximando ao propósito explícito de alcançar uma tradução que já não seja apenas de palavras, mas de mundos (translating worlds). Uma forma de conceber esta expansão de grau maior é na forma de uma escala superior no muito influente esquema que Jakobson expõe no seu texto "Sobre os aspectos linguísticos da tradução". Aos níveis estabelecidos aí da tradução intralingual (rewording), inter-lingual (translation proper, tradução propriamente dita) e intersemiótica (transmutation), viria a somar-se o vértice da transmutação propriamente dita, nos termos de Carlo Severi (2014, p. 47). Não é possível aqui analisar em detalhes as implicações ontológicas desta proposição, mas vou referir-me mais adiante a um aspecto dela.

Em outro dos artigos do dossiê, Geoffrey Lloyd se ocupa não apenas da eficácia da tradução, mas também do que ela demanda. Concretamente, Lloyd enfatiza que aceder ao que pode a tradução requer revisar e colocar em suspenso um conjunto de conceitos que estruturam o mundo em que vivemos:

[...] it is up to observers, to us, to see what we can learn from the exercise of investigating their ways [of the natives] of being in the world. That means suspending dis- 
belief and being prepared to revise just about everything we normally take for granted about those key concepts of person, agency, causation, space, time and, yes, certainly, nature. (LLOYD, 2014, p. 231).

A exposição à eficácia da tradução só chega a acontecer, segundo Lloyd, a custo de uma desestabilização de pressupostos muito enraizados. O que resulta evidente se consideramos que a tradução seria simplesmente bloqueada ou neutralizada ou se tornaria inócua caso ela tope, do outro lado, com uma disposição tão segura de si mesmo como tão pouco disposta à menor variação. O que uma tradução pode nos oferecer é proporcional à margem de abertura de nossos conceitos. A exposição ao impacto dos conceitos nativos de alteridade não demanda tolerância, de modo que apenas se lhes conceda lugar, mas outra coisa: a disposição a assumir o eventual desafio de um reordenamento conceitual.

Não se pode insistir o suficiente nas implicâncias desta mudança de disposição sugerida por Lloyd. Pois o que está em jogo, junto com uma maior receptividade das diferenças, é a admissão de um grau inversamente proporcional de precariedade nas pretensões de identidade. Deixar oscilar conceitos profundamente enraizados, ainda quando de fato isso sempre tenha acontecido, supõe um considerável esforço de desprendimento. E é nesse ponto onde me parece que a proposta de Severi revela-se insuficientemente radical como para acompanhar a disseminação da tradução. A fórmula de uma "transmutação propriamente dita" (SEVERI, 2014, p. 47) arrasta na sua formulação compromissos muito fortes justamente com algumas dessas pressuposições que Lloyd gostaria de ver em suspensão. É muito nesta transmutação “propriamente dita", por exemplo, o que depende da categoria do próprio e da propriedade, cuja ênfase lhe confere sua marca distintiva e sem o qual aparentemente viria a ser uma transmutação comum. A crítica de Derrida (1985, p. 100) a Jakobson apontava justamente contra essa fórmula da tradução propriamente dita e para sua pressuposição associada de línguas supostamente autônomas, so- 
beranas, idênticas a si mesmas e propriamente constituídas. Tais formulações põem em evidencia, a meu ver, a encruzilhada entre buscar a extrapolação da tradução sob a premissa da propriedade ou buscá-la sob o risco da impropriedade, ou seja, por via da transformação e do acesso da iniciação.

\section{III}

Tudo isso nos leva de volta ao princípio, quero dizer à pressuposição de um princípio que também aparece na proposição geral de Carlo Severi e William Hanks sobre a tradução como princípio epistemológico geral. Apelar à ideia de um princípio supõe decisões, explícitas ou não, no que diz respeito ao menos a modos de fundamentação e de governo ou controle justamente sob a forma do predomínio de um princípio. Com isso se trata, de novo, de uma categoria fortemente ancorada na conceitualidade ocidental dominante que, a falta de outras indicações, o que dá a entender sob a ideia de princípio é o desenvolvimento de uma idealidade que, ao mesmo tempo, se mantem única e idêntica a si mesma. Mas é possível conceber, efetivamente, a incessante inquietude e o efeito proliferativo da tradução sob o governo de um princípio?

Talvez seja necessário buscar alternativas em outras constelações conceituais, das quais gostaria de mencionar, para finalizar, uma possível. Giorgio Agamben tem retomado a ideia da potencialidade aristotélica e a radicalizado enfatizando sua carga de negatividade ( $c f$. Agamben 1999, cap. 11). O ponto de partida é a distinção entre uma potência genérica, por exemplo, a de uma criança de converter-se num adulto, e outra potência facultativa, por exemplo a de um arquiteto, que tem a faculdade de construir uma casa, ainda quando atualmente não o esteja fazendo. Agamben cita a esse respeito uma passagem notável onde Aristóteles diz: "What is potential is capable of not being in actuality. What is potential can both be and not be, for the same is potential both to be and not to be" (Metaphysics 1050 B10 apud AGAMBEN, 1999, p. 
182). E é daí que Agamben levanta a mútua incumbência, o mútuo requerimento da potencialidade e da negatividade.

Estes desdobramentos da potencialidade passam habitualmente despercebidos porque, evidentemente, no momento da atualidade é o cumprimento de algo o que chama primeiramente a atenção. Mas há na potencialidade algo que excede a atualidade: a ressonância do não ser. A isso aponta Agamben evocando as interpretações musicais de Glenn Gould. Há na arte de Gould algo que excede o virtuosismo de um pianista que se limita a atualizar uma composição por mais árdua que seja - e esse algo é a parte ou o rumor do não ser. Diz Agamben: "se é próprio de todo pianista tocar e não tocar, Glenn Gould é, no entanto, o único que pode não não-tocar (...) toca, por assim dizer, com a sua potência de não tocar" (1993, p. 34).

E esta passagem - ou novo (e aqui: último) rodeio - me parece que nos reconduz, ou pode fazê-lo, a motivos de traduzir. A tradução, segundo isso, também pode ser vista como uma faculdade de transformação e acesso, e como uma potência negativa na medida em que nos mostra os limites de toda atualização. No incessante desassossego da tradução sobrevive o não-ser enquanto dimensão inesgotável das coisas. E tal como na frase de Gould citada na epígrafe, essa inquietude abre ao mesmo tempo um interminável debate acerca do que pode um lugar de pertença. 


\section{Referências}

AGAMBEN, G. A comunidade que vem. Tradução de Antonio Guerreiro. Lisboa: Editorial Presença, 1993.

. Potentialities. Collected Essays in Philosophy. Edited and translated by Daniel Heller-Roazen. Stanford University Press, 1999

BENJAMIN, W. “A tarefa do tradutor”. Tradução de Susana Kampff Lages. In: HEIDERMANN, W. (Org): Clássicos da Teoria da Tradução. Volume 1: Alemão-Português. 2a edição, revisada e ampliada. Florianópolis: UFSC/Núcleo de Pesquisas em Literatura e Tradução, 2010.

DERRIDA, J. The Ear of the Other. Otobiography, Transference, Translation. Translated by Peggy Kamuf and edited by Christie McDonald and Claude Levesque. Lincoln and London: University of Nebraska Press, 1985.

EAGLETON, T. Figures of Dissent. London: Verso, 2003.

HANKS, W. "The space of translation". In: Hau: Journal of Ethnographic Theory, Edinburgh, Vol 4, No 4. 2014. Disponível em: http://www.haujournal.org/ index.php/hau/issue/view/hau4.2. Acesso em: 13 jan.2016.

HANKS, W; SEVERI, C. (eds). Translating Worlds - The epistemological space of translation. Chicago: The University of Chicago Press, 2015.

KOPENAWA, D; ALBERT, B. La chute du ciel. Paroles d'un chaman yanomani, préface de Jean Malaurie. Paris: Plon, 2010.

. The falling sky: words of a Yanomami shaman. Translated by N. Elliot \& A. Dundy. Massachusets-London: Belknap Press, 2013.

. A queda do céu. Palavras de um xamã yanomami. Tradução de Beatriz Perrone-Moisés, prefácio de Eduardo Viveiros de Castro. São Paulo: Companhia das Letras, 2015. 
LLOYD, G. „On the very possibility of mutual intelligibility“. In: Hau: Journal of Ethnographic Theory, Edinburgh, Vol 4, No 4. 2014. Disponível em: http:// www.haujournal.org/index.php/hau/issue/view/hau4.2. Acesso em: 13 jan.2016.

MEILLASSOUX, Q. Après la finitude : essai sur la nécessite de la contingence. Paris: Seuil, 2008.

SEVERI, C. „Transmutating beings: A proposal for an anthropology of thought“. In: Hau: Journal of Ethnographic Theory, Edinburgh, Vol 4, No 4. 2014. Disponível em: http://www.haujournal.org/index.php/hau/issue/view/hau4.2. Acesso em: 13 jan.2016.

SEVERI, C; HANKS, W. „Translating Worlds: The epistemological space of translation“. In: Hau: Journal of Ethnographic Theory, Edinburgh, Vol 4, No 4. 2014. Disponível em: http://www.haujournal.org/index.php/hau/issue/view/ hau4.2. Acesso em: 13 jan.2016.

VALÉRY, P. Eupalinos ou o Arquiteto. Tradução de Olga Reggiani. Edição bilíngüe francês/português. Rio de Janeiro: Ed. 34, 1996.

Recebido em: 12/02/2016

Aceito em: 11/06/2016 Publicado em setembro de 2016 